\title{
Article \\ A Calculation Model for Cooling Rate of Aluminum Alloy Melts during Continuous Rheo-Extrusion
}

\author{
Yu Wang ${ }^{1,2}$, Minqiang Gao ${ }^{2, *}$, Bowei Yang ${ }^{1}$, Jingyuan Bai ${ }^{1}$ and Renguo Guan ${ }^{2, *}$ \\ 1 Key Laboratory of Lightweight Structural Materials Liaoning Province, School of Materials Science and \\ Engineering, Northeastern University, Shenyang 110819, China; neu_wangyu@yeah.net (Y.W.); \\ ybw_neu@163.com (B.Y.); Baekkyungwon@163.com (J.B.) \\ 2 Engineering Research Center of Continuous Extrusion, Ministry of Education, Dalian Jiaotong University, \\ Dalian 116028, China \\ * Correspondence: mqgao@djtu.edu.cn (M.G.); guanrenguo@sina.cn (R.G.)
}

Citation: Wang, Y.; Gao, M.; Yang, B. Bai, J.; Guan, R. A Calculation Model for Cooling Rate of Aluminum Alloy Melts during Continuous Rheo-Extrusion. Materials 2021, 14 , 5684. https://doi.org/10.3390/ ma14195684

Academic Editor: A.

Javier Sanchez-Herencia

Received: 20 July 2021

Accepted: 27 September 2021

Published: 29 September 2021

Publisher's Note: MDPI stays neutral with regard to jurisdictional claims in published maps and institutional affiliations.

Copyright: (c) 2021 by the authors. Licensee MDPI, Basel, Switzerland. This article is an open access article distributed under the terms and conditions of the Creative Commons Attribution (CC BY) license (https:// creativecommons.org/licenses/by/ $4.0 /)$.

\begin{abstract}
The melt temperature of aluminum alloys plays a significant role in determining the microstructure characteristic during continuous rheo-extrusion. However, it is difficult to measure the actual melt temperature in the roll-shoe gap. In this work, based on the basic theory of heat transfer, a calculation model for heat transfer coefficient of cooling water/roll interface and melt/roll interface is established. In addition, the relationship between the temperature at the melt/roll interface and the velocity of cooling water is investigated. Combined with the CALPHAD calculation, the melt temperature during solidification in the continuous rheo-extrusion process is calculated. Using this model, the cooling rate of an Al-6Mg (wt.\%) alloy melt prepared by continuous rheo-extrusion is estimated to be $10.3 \mathrm{~K} / \mathrm{s}$. This model used to determine the melt parameters during solidification provides a reference for optimizing the production process of continuous rheo-extrusion technology.
\end{abstract}

Keywords: aluminum alloy; continuous rheo-extrusion; heat transfer; solidification; cooling rate

\section{Introduction}

Green, energy-saving and efficient processing technology has been developed rapidly in recent decades [1-3]. Continuous rheo-extrusion technology is an advanced technology that can be directly used for continuous preparation of aluminum alloy billets and pipes and realize one-step forming from casting to finished products [4]. Compared with the traditional casting coupled with deformation processing technologies, the continuous rheo-extrusion technology possesses the advantage of reducing the capital cost, energy consumption, operation cost and scrap rate.

During the continuous rheo-extrusion process for preparing aluminum alloys, the melt flows out of the tundish and enters into the roll-shoe gap, and then solidifies due to the cooling effect caused by the water-cooled roll and the shoe. The roll is cooled by circulating water, which offers a high cooling rate during solidification. Many studies have shown that the cooling rate has an important effect on the as-cast microstructure of alloys during solidification. The average size of grains [5], primary and/or secondary dendrite arm spacing [6], morphology and distribution of secondary phases [7], and solid solubility of alloying element [8] are proved to be affected by cooling rate. Therefore, it is necessary to determine the temperature variation of the melt, especially the influence of rotating speed and cooling water velocity on the cooling rate. Orthogonal experiments were carried out to measure the melt temperature varied with the rotating speed or the cooling water velocity $[9,10]$. However, it is difficult to measure the melt temperature in the roll-shoe gap during the continuous rheo-extrusion process. Therefore, it is important to establish a cooling rate calculation model for the molten metal. The distribution of temperature field, solidification rate and cooling rate in the solidification process mainly depend on the interface heat transfer coefficient between the metal and mold [11-14]. Due to the 
complexity of interface morphology and the uncertainty of the heat transfer mechanism in the gap, there is no effective method for quantitatively describing the interface heat transfer coefficient. Cheung et al. [15] proposed a method to establish the expression of the metal/mold interface heat transfer coefficient of the rotary continuous caster. However, for the continuous rheo-extrusion process, the influence of the heat transfer capacity of the roll and the cooling system in the roll cannot be ignored.

Al-Mg alloys (5XXX aluminum alloys) are used to be welding wires [16,17]. Compared with pure aluminum and 6XXX aluminum alloys, due to the limitation of deformation capability, there are problems for 5XXX aluminum alloys with a high $\mathrm{Mg}$ content prepared by rheo-extrusion, such as low product efficiency and poor quality. Therefore, it is necessary to explore the preparation process, thus optimizing the property of alloys. In this work, a calculation model for the cooling rate of aluminum alloy melts during continuous rheoextrusion based on the theory of heat transfer is developed. Combined with the CALPHAD calculation, the melt temperature during solidification in the continuous rheo-extrusion process is calculated. The melt temperature of an $\mathrm{Al}-6 \mathrm{Mg}$ alloy is estimated via this model. The aim of this work is to realize the continuous rheo-extrusion process optimization and to provide a reference for simulation research.

\section{Calculation Model and Governing Equations}

The schematic physical model of the continuous rheo-extrusion process is shown in Figure 1. Solidification is the main process of transferring heat from the high-temperature melt to the roll and shoe, including the process of liquid-solid transformation. In order to simplify the calculation, the following basic hypotheses are proposed as follows:

1. The process is a continuous and stable process. The impact, leakage and flow undulation of melt at the initial and finishing stages are neglected.

2. The melt is incompressible viscoplastic material, and the volume constancy is satisfied.

3. The temperature of the roll and shoe surfaces contacting to melt is considered as the constant.

4. The heat transfer by the water in the inlet and outlet pipes is ignored.

5. The temperature of the sections where the cooling water pipe contacting with the roll is considered to be identical.

6. The flow velocity in the cooling water pipes is uniform, and the velocity of water is regarded as a constant value at the same geometric position.

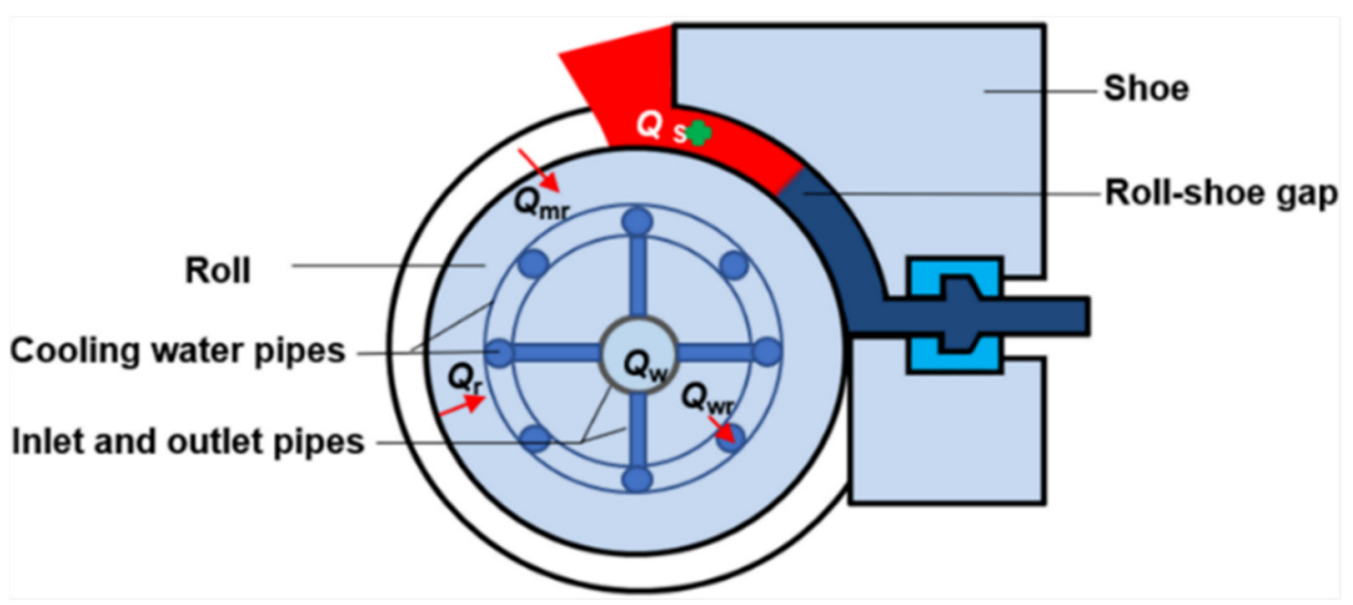

Figure 1. Schematic physical model of the continuous rheo-extrusion process.

During the solidification process of melt in the roll-shoe gap, there are two parts of heat that will mainly be transferred away by the roll, the release of latent heat and the 
heat comes from the decrease in the melt temperature. The energy relation equation is expressed as

$$
Q_{\mathrm{mr}}=Q_{\mathrm{m}}+Q_{\mathrm{s}}
$$

where $Q_{\mathrm{m}}$ is the released heat due to the decrease in melt temperature. It is well known that, in unit time, when the melt temperature decreases, the calculation formula of heat emission can be given by

$$
Q_{\mathrm{m}}=c_{\mathrm{m}} \rho_{m} l_{\mathrm{m}}^{2}\left(T_{\mathrm{m} 0}-T_{\mathrm{m}}\right)
$$

where $c_{\mathrm{m}}$ and $\rho_{m}$ are the specific heat capacity and density of melt, respectively, $l_{\mathrm{m}}$ is the length of the cross-section of the roll-shoe gap, $T_{\mathrm{m} 0}$ is the initial temperature of melt that is equal to the pouring temperature, and $T_{\mathrm{m}}$ is the actual melt temperature in the roll-shoe gap. The classic expression of the release of latent heat between liquidus and solidus temperatures is expressed as follows:

$$
Q_{\mathrm{s}}=\rho_{m} l_{\mathrm{m}}^{2} L_{\mathrm{m}} f_{\mathrm{s}}
$$

where $L_{\mathrm{m}}$ is the latent heat and $f_{\mathrm{s}}$ is the local solid fraction.

The melt heat in the roll-shoe gap is mainly conducted by convective heat $\left(Q_{\mathrm{mr}}\right)$ exchange at the melt/roll interface, which can be given by [18] (pp. 7-9)

$$
Q_{\mathrm{mr}}=4 h_{\mathrm{mr}} l_{\mathrm{m}} \tau\left(T_{\mathrm{m}}-T_{\mathrm{r} 2}\right)
$$

where $h_{\mathrm{mr}}$ is the heat transfer coefficient acting at the melt/roll interface, and $\tau$ is the heat conduction time.

By substituting Equations (2)-(4) into Equation (1), the calculation formula of melt temperature is obtained as follows:

$$
T_{\mathrm{m}}=\left(4 h_{\mathrm{mr}} \tau T_{\mathrm{r} 2}+c_{\mathrm{m}} \rho_{\mathrm{m}} l_{\mathrm{m}} T_{\mathrm{m} 0}+\rho_{\mathrm{m}} l_{\mathrm{m}} L_{\mathrm{m}} f_{\mathrm{s}}\right) /\left(4 h_{\mathrm{mr}} \tau+c_{\mathrm{m}} \rho_{\mathrm{m}} l_{\mathrm{m}}\right)
$$

Based on the previous work, the expression of $h_{\mathrm{mr}}$ calculated as follows [15]:

$$
h_{\mathrm{mr}}=\alpha \tau^{-m}
$$

where $\alpha$ and $m$ are constants. Therefore, it is necessary to determine the temperature of roll at the melt/roll interface.

The internal heat transfer process of the roll can be simplified as a cylinder heat transfer model, as shown in Figure 2.

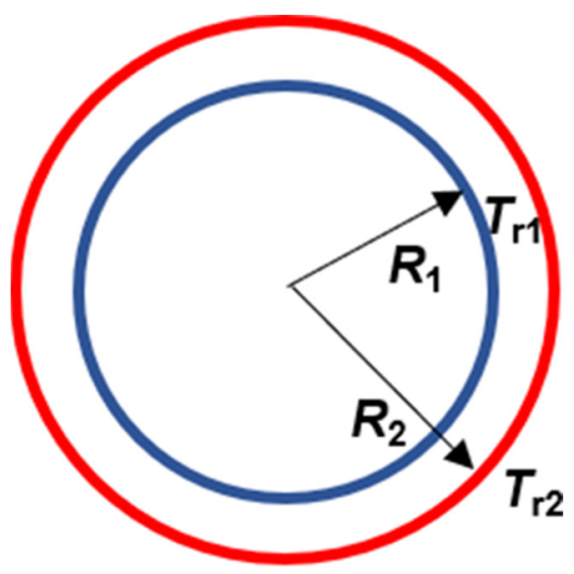

Figure 2. Diagram of the simplified model of the cylinder heat transfer model.

It is considered that the heat conduction along the axial direction is negligible, and the temperature only changes along the radial direction. In addition, the temperature of 
roll and shoe surface contacting to melt is considered to be a constant. Thus, the heat conduction inside the roll is described by [18] (pp. 136-154)

$$
Q_{\mathrm{r}}=\frac{2 \pi \lambda_{\mathrm{r}} l_{3}\left(T_{\mathrm{r} 1}-T_{\mathrm{r} 2}\right)}{\ln \left(R_{2} / R_{1}\right)}
$$

where $\lambda_{\mathrm{r}}$ is the heat conductivity of the low-carbon steel roll, $l_{3}$ is the length that is shown in Figure 3, $T_{\mathrm{r} 1}$ is the roll temperature at the cooling water/roll interface, $T_{\mathrm{r} 2}$ is the roll temperature at the melt/roll interface, $R_{1}$ is the roll radius at the cooling water pipes position, and $R_{2}$ is the roll outside radius.

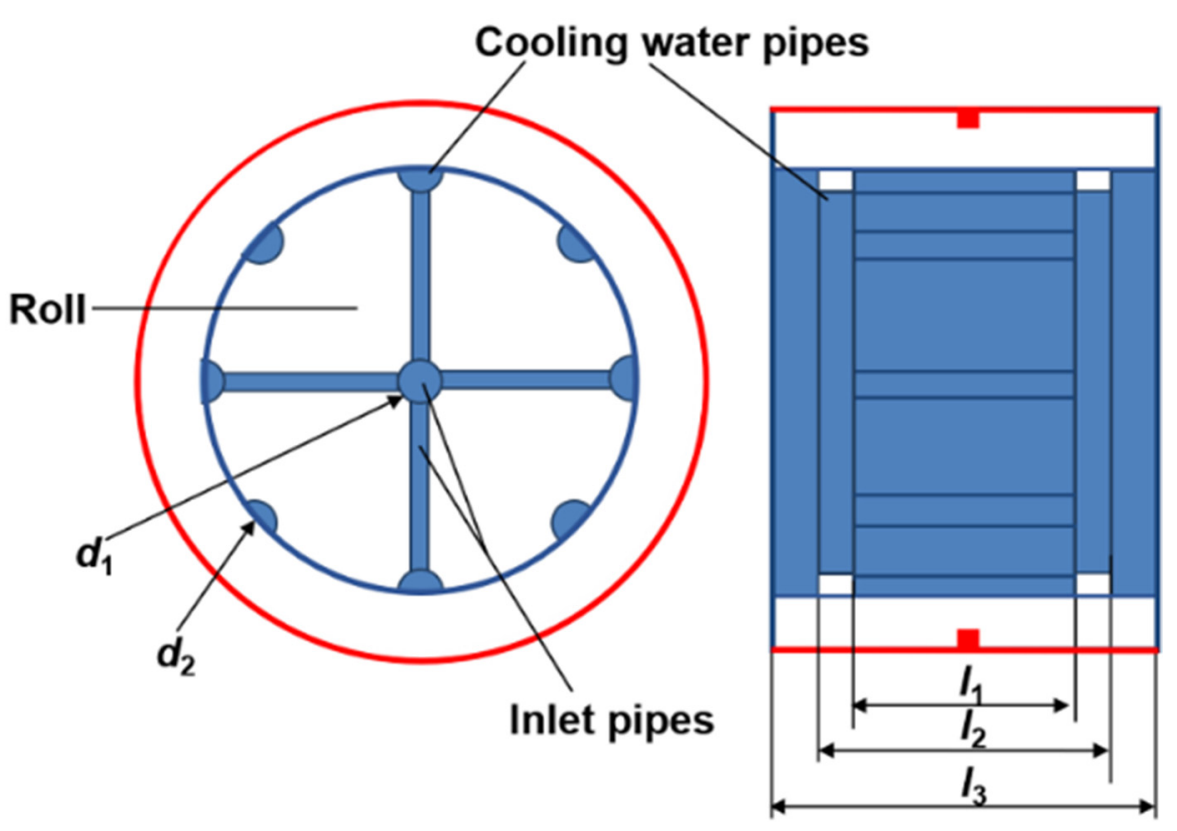

Figure 3. Distribution diagram of the cooling water system in the roll.

Heat transfer between the melt and roll is the key part of the melt treatment. According to Equation (4), the heat transfer during solidification is mainly determined by the two key factors, i.e., the heat transfer coefficient and the roll temperature at the melt/roll interface. In addition, the heat transfer coefficient at the melt/roll interface is also significantly affected by the temperature of the roll at the melt/roll interface. As shown in Figure 3, it is very difficult to directly detect the roll surface temperature in practical applications owing to the complex structure of the equipment. The cooling water system in the roll determines the roll temperature field. By measuring the temperature before and after the cooling water flowed through the roll and the flow rate, the energy taken away by cooling water can be calculated. Thus, the roll temperature can be estimated by combining the energy equation (Equation (1)) with the heat conduction law in the roll (Equation (7)). According to Equation (7), the expression of the roll surface temperature can be written as

$$
T_{\mathrm{r} 2}=T_{\mathrm{r} 1}-\frac{Q_{\mathrm{r}} \ln \left(R_{2} / R_{1}\right)}{-2 \pi \lambda_{\mathrm{r}} l_{3}}
$$

According to the principle of energy conservation, the heat $\left(Q_{\mathrm{w}}\right)$ taken away by the cooling water is equal to the convective heat $\left(Q_{\mathrm{wr}}\right)$ at the cooling water/roll interface. They also equal the conduction heat $\left(Q_{\mathrm{r}}\right)$ inside the roll and the convective heat $\left(Q_{\mathrm{mr}}\right)$ at the melt/roll interface. Thus, there is an equivalence relation as follows:

$$
Q_{\mathrm{w}}=Q_{\mathrm{wr}}=Q_{\mathrm{r}}=Q_{\mathrm{mr}}
$$


$Q_{\mathrm{w}}$ can be calculated as [18] (pp. 523-525)

$$
Q_{\mathrm{w}}=c_{\mathrm{w}} \rho_{\mathrm{w}} u_{\mathrm{w}} \pi\left(\frac{d_{1}}{2}\right)^{2}\left(T_{\mathrm{w} 2}-T_{\mathrm{w} 1}\right)
$$

where $c_{\mathrm{W}}$ is the specific heat capacity of cooling water, $\rho_{\mathrm{W}}$ is the density of the cooling water, $u_{\mathrm{w}}$ is the velocity of cooling water in the inlet pipe, $d_{1}$ is the diameter of the cooling water inlet pipe, $T_{\mathrm{w} 1}$ is the inlet temperature of cooling water, and $T_{\mathrm{w} 2}$ is the outlet temperature of cooling water.

According to Newton's law of cooling, $Q_{\mathrm{wr}}$ can be expressed as follows [18] (pp. 112-115):

$$
Q_{\mathrm{wr}}=\sum h_{\mathrm{wr}} A_{\mathrm{wr}}\left(T_{\mathrm{rl}}-T_{\mathrm{w}}\right)
$$

where $h_{\mathrm{wr}}$ is the heat transfer coefficient acting at the cooling water/roll interface, $A_{\mathrm{wr}}$ is the area of contact surface at the cooling water/roll interface, $T_{\mathrm{w}}$ is the temperature of the cooling water at the cooling water/roll interface, and $T_{\mathrm{w}}$ is given by

$$
T_{\mathrm{w}}=\frac{T_{\mathrm{wl}}+T_{\mathrm{w} 2}}{2}
$$

Based on Equation (11), the heat transfer coefficient acting at the cooling water/roll interface $\left(h_{\mathrm{wr}}\right)$ should be determined firstly, and then the convective heat $\left(Q_{\mathrm{wr}}\right)$ at the cooling water/roll interface can be calculated. To simplify the calculation, the heat transfer between the water in inlet pipes and the roll is ignored. In addition, it is assumed that the flow velocity of cooling water in inlets pipes is a constant, and the flow velocity of cooling water in the distributed pipes with the same special positions is identical. It can be seen that the convective heat $Q_{\mathrm{wr}}$ at the cooling water/roll interface can be divided into two parts. One part is the heat taken away by the cooling water in the pipes parallel to the axis of roll, and the other part is the heat taken away by the cooling water in the pipes vertical to the axis of the roll. Therefore, the convective heat $Q_{\mathrm{wr}}$ in this system is expressed as

$$
Q_{\mathrm{wr}}=\sum h_{\mathrm{wr}} A_{\mathrm{wr}}\left(T_{\mathrm{rl}}-T_{\mathrm{w}}\right)=\left(h_{\mathrm{wr} 1} A_{\mathrm{wr} 1}+h_{\mathrm{wr} 2} A_{\mathrm{wr} 2}\right)\left(T_{\mathrm{rl}}-T_{\mathrm{w}}\right)
$$

where $h_{\mathrm{wr} 1}, A_{\mathrm{wr} 1}$ and $h_{\mathrm{wr} 2}, A_{\mathrm{wr} 2}$ are the convective heat transfer coefficient and the interface area corresponding to the pipes parallel and vertical to the axis of roll, respectively. The expression of convective heat transfer coefficient is given by [18] (pp. 436-441)

$$
h=\frac{\lambda}{d} N u
$$

where $d$ is the diameter of the cooling water pipe. The velocity of cooling water in the inlet pipe, the velocity of cooling water in the pipes parallel and vertical to the axis of the roll are $u_{\mathrm{w}}, u_{\mathrm{w} 1}$ and $u_{\mathrm{w} 2}$, respectively. The equal volume of cooling water can be described as follows:

$$
\pi\left(\frac{d_{1}}{2}\right)^{2} u_{\mathrm{w}}=8 \frac{l_{2}-l_{1}}{2} \frac{d_{2}}{2} u_{\mathrm{w} 2}=8 \frac{1}{2} \pi\left(\frac{d_{2}}{2}\right)^{2} u_{\mathrm{w} 1}
$$

where $d_{1}$ is the diameter of the cooling water inlet pipe, $d_{2}$ is the diameter of the cooling water pipe parallel to the axis of the roll, $l_{1}$ and $l_{2}$ are the lengths that are shown in Figure 3 .

The well-known calculation formula of Reynolds number $\left(R_{e}\right)$ is described as follows [18] (pp. 434-441):

$$
\operatorname{Re}=\frac{u d}{v}
$$

where $u$ is the viscosity of cooling water, and $v$ is the motion viscosity of cooling water. The $R e$ value is an empirical value to judge the turbulent or laminar flow in a smooth tube. In this case, the critical $R e$ value is $10^{4}$ [19] (pp. 246-249). The equivalent diameters of the cooling water pipe parallel and vertical to the axis of the roll are $d_{3}$ and $d_{4}$, respectively. 
In addition, the value of $v$ is taken as the water motion viscosity at the average fluid bulk temperature $\left(T_{\mathrm{w}}\right)$, thus the critical viscosities of $u_{\mathrm{w} 1}$ and $u_{\mathrm{w} 2}$ are $5.1538 \mathrm{~m} / \mathrm{s}$ and $6 \mathrm{~m} / \mathrm{s}$, respectively. Considering the actual situation, the viscosity of cooling water in the inlet pipe is below $5 \mathrm{~m} / \mathrm{s}$, therefore, only the heat transfer in the laminar flow system is studied.

A simper relation proposed by Sieder and Tate for laminar heat transfer in tubes is shown as Equation (17), which can be used to calculate the $\mathrm{Nu}$ corresponding to the pipes parallel to the axis of the roll [19] (pp. 252).

$$
N u_{1}=1.86\left(\frac{\operatorname{RePr}}{1 / d}\right)^{1 / 3}\left(\frac{\mu_{\mathrm{w}}}{\mu_{\mathrm{r}}}\right)^{0.14}
$$

where Prandtl number (Pr) [18] (pp. 407-409) is defined as the ratio of the kinematic viscosity $(v)$ to the thermal diffusivity $(\alpha)$, and the expression is

$$
\operatorname{Pr}=\frac{v}{\alpha}=\frac{\mu c}{\lambda}
$$

The pipes parallel to the axis of the roll are circular, and a correction factor $C_{r}=1+10.3\left(\frac{d}{R}\right)^{3}$ is introduced to Equation (17), thus the $N u_{2}$ can be written as [19] (pp. 248-249)

$$
N u_{2}=\left[1+10.3\left(\frac{d}{R}\right)^{3}\right] 1.86\left(\frac{\operatorname{RePr}}{1 / d}\right)^{1 / 3}\left(\frac{\mu_{\mathrm{w}}}{\mu_{\mathrm{r}}}\right)^{0.14}
$$

Substituting Equations (17) and (19) into Equation (14), respectively:

$$
\begin{aligned}
& h_{\mathrm{wr} 1}=\frac{\lambda_{\mathrm{w}}}{d_{3}} N u_{1}=\frac{\lambda_{\mathrm{w}}}{d_{3}} 1.86\left(\frac{0.16 u_{\mathrm{w}} d_{1}}{v_{\mathrm{w}}} \cdot \frac{P r}{1 / d_{3}}\right)^{1 / 3}\left(\frac{\mu_{\mathrm{w}}}{\mu_{\mathrm{r}}}\right)^{0.14} \\
& h_{\mathrm{wr} 2}=\frac{\lambda_{\mathrm{w}}}{d_{4}} N u_{2}=\frac{\lambda_{\mathrm{w}}}{d_{4}}\left[1+10.3\left(\frac{d_{2}}{R}\right)^{3}\right] 1.86\left(\frac{0.04 \pi u_{\mathrm{w}} d_{2}}{v_{\mathrm{w}}} \cdot \frac{\operatorname{Pr}}{1 / d_{4}}\right)^{1 / 3}\left(\frac{\mu_{\mathrm{w}}}{\mu_{\mathrm{r}}}\right)^{0.14}
\end{aligned}
$$

\section{Results and Discussion}

Figure 4 shows the curves of convective heat transfer coefficients varied with the velocity of cooling water. The fluid properties are calculated at the average temperature of cooling water. When $T_{\mathrm{w} 1}$ and $T_{\mathrm{w} 2}$ are taken as $15^{\circ} \mathrm{C}$ and $25^{\circ} \mathrm{C}$, respectively, then $T_{\mathrm{w}}$ is $20{ }^{\circ} \mathrm{C}$. The physical property constants of water at $20^{\circ} \mathrm{C}$ are listed in Table 1 . It can be seen that with the increase in cooling water velocity, the convective heat transfer coefficients increase gradually, and the heat transfer coefficients in laminar flow are below $1200 \mathrm{~W} /\left(\mathrm{m}^{2} \cdot \mathrm{K}\right)$.

Table 1. Physical parameters of cooling water at $20^{\circ} \mathrm{C}[19]$ (p. 563).

\begin{tabular}{cc}
\hline Density $\rho_{\mathbf{W}}, \mathbf{k g} / \mathbf{m}^{3}$ & $\mathbf{9 . 9 8 2} \times \mathbf{1 0}^{\mathbf{2}}$ \\
\hline Constant pressure specific heat capacity, $c_{\mathrm{W}}, \mathrm{J} /(\mathrm{kg} \cdot \mathrm{K})$ & $4.183 \times 10^{3}$ \\
Motion viscosity, $v_{\mathrm{W}}, \mathrm{m}^{2} / \mathrm{s}$ & $1.006 \times 10^{-6}$ \\
Thermal conductivity, $\lambda_{\mathrm{W}}, \mathrm{W} /(\mathrm{m} \cdot \mathrm{K})$ & 0.599 \\
Viscosity, $\mu_{\mathrm{w}}, \mathrm{Pa} \cdot \mathrm{s}$ & $1.004 \times 10^{-9}$ \\
\hline
\end{tabular}




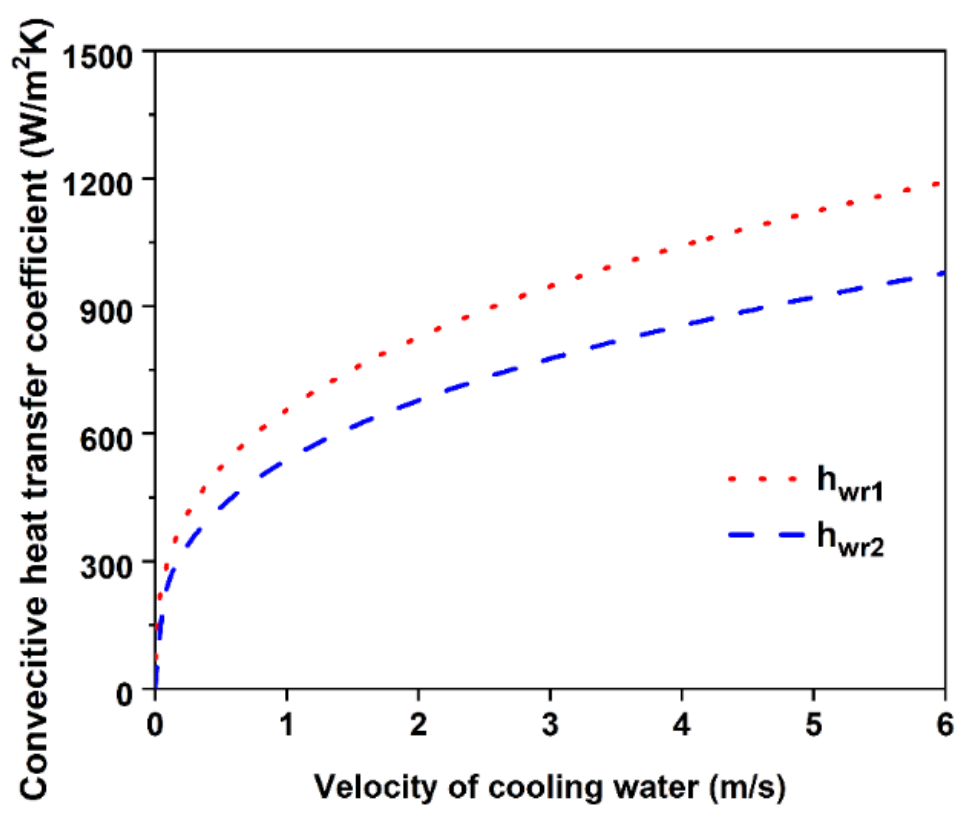

Figure 4. Curves of convective heat transfer coefficients varied with velocity of cooling water.

The temperature of roll at the cooling water/roll interface $\left(T_{\mathrm{r} 1}\right)$ can be obtained by combining Equations (9)-(11):

$$
T_{\mathrm{r} 1}=\frac{{ }_{\mathrm{w}} \rho_{\mathrm{w}} u_{\mathrm{w}} \pi\left(\frac{d_{1}}{2}\right)^{2}\left(T_{\mathrm{w} 2}-T_{\mathrm{w} 1}\right)}{\sum h_{\mathrm{wr}} A_{\mathrm{wr}}}+\frac{T_{\mathrm{w} 1}+T_{\mathrm{w} 2}}{2}
$$

The curve of $T_{\mathrm{r} 1}$ varied with cooling water velocity is shown in Figure 5 . It can be seen that the roll temperature at the cooling water/roll interface increases with the increase in cooling water velocity and increases when the velocity of cooling water is increased. When the temperature increment of cooling water is fixed, the greater the cooling water velocity is, the more heat the cooling water takes away in unit time. Moreover, the heat transfer process is associated with the thermal conductivity of roll [20]. Therefore, only when enough heat is transferred in the roll, can the heat transfer increment caused by the increase of cooling water velocity be satisfied. Therefore, there is a large temperature gradient in the roll to meet the condition, and the temperature of the roll at the melt/roll interface will also increase with the increase in cooling water velocity.

By substituting Equation (22) into Equation (10), the calculation formula of the roll temperature at melt/roll interface is given as follows:

$$
T_{\mathrm{r} 2}=c_{\mathrm{w}} \rho_{\mathrm{w}} u_{\mathrm{w}} \pi\left(\frac{d_{1}}{2}\right)^{2}\left(T_{\mathrm{w} 2}-T_{\mathrm{w} 1}\right)\left[\frac{1}{\sum h_{\mathrm{wr}} A_{\mathrm{wr}}}-\frac{\ln \left(R_{2} / R_{1}\right)}{-2 \pi \lambda_{\mathrm{r}} l}\right]+\frac{T_{\mathrm{w} 1}+T_{\mathrm{w} 2}}{2}
$$

The curve of $T_{\mathrm{r} 2}$ varied with cooling water velocity is shown in Figure 6 . The rule shown by the curve is that the roll temperature at the cooling water/roll interface increases with the increase of cooling water velocity. As stated above, there is a large temperature gradient in the roll. Although the cooling water is laminar, and the heat transfer efficiency of the contact interface between the cooling water and the extrusion roller is low. There is a high-temperature gradient in the roll to achieve the required heat transfer efficiency. 


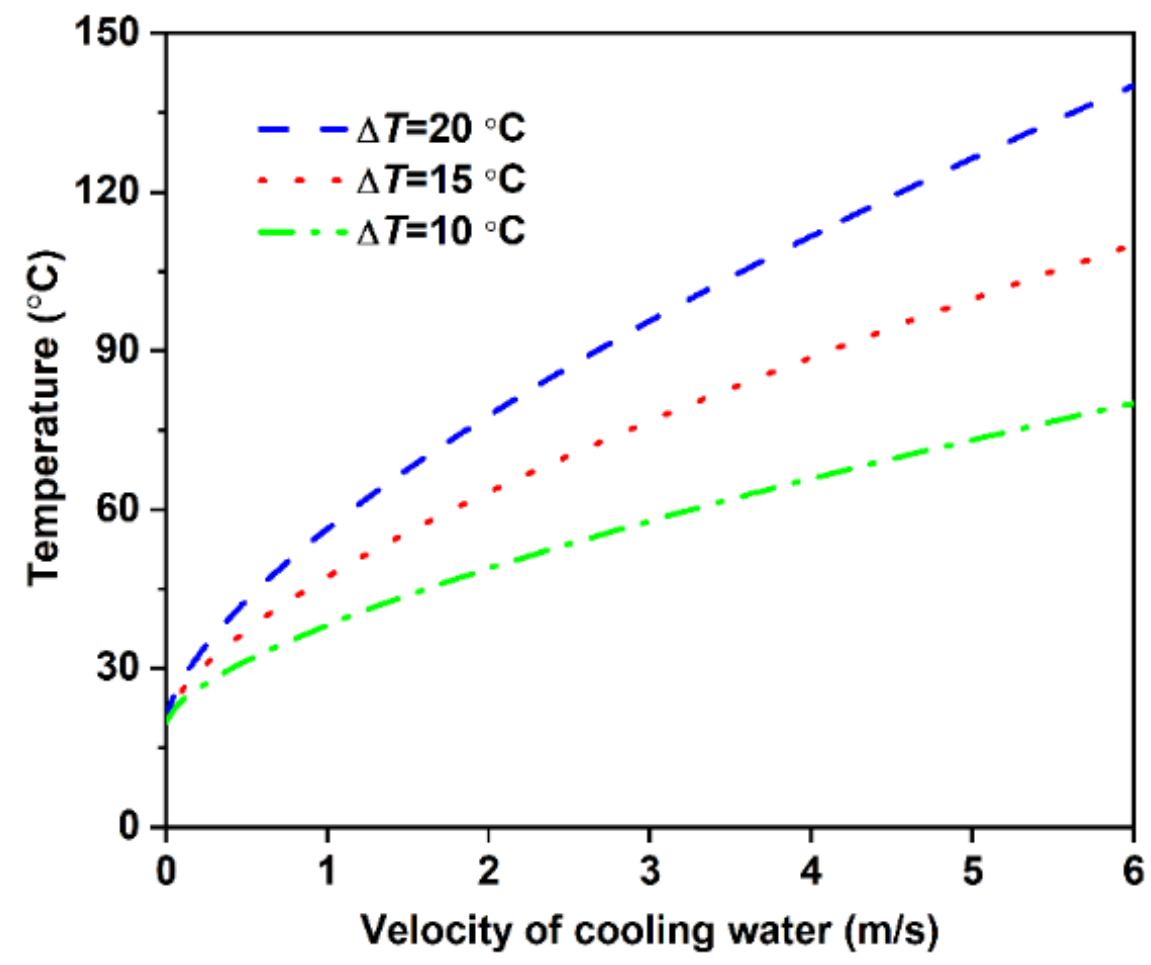

Figure 5. Roll temperature at the cooling water/roll interface as a function of velocity of cooling water.

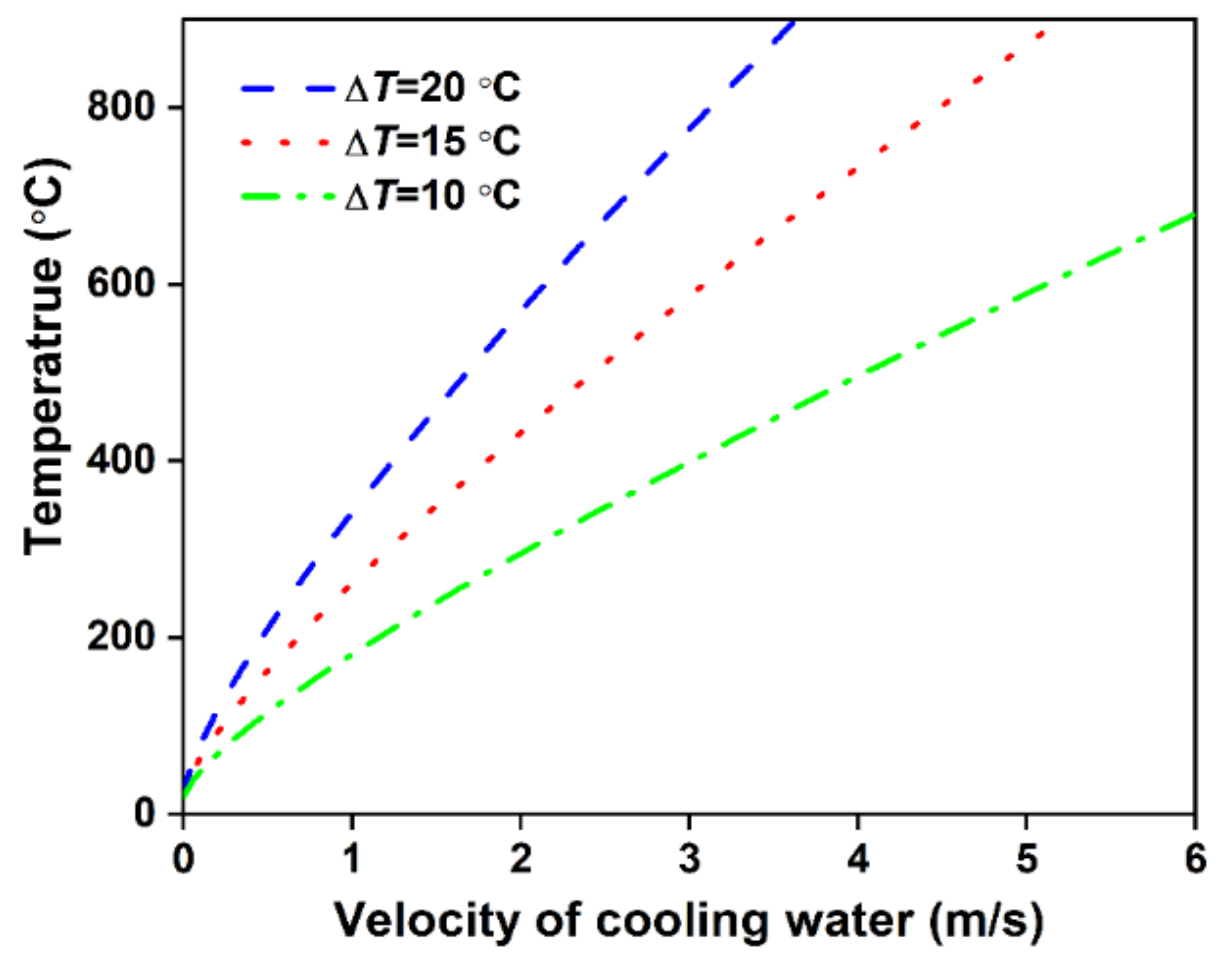

Figure 6. Relationship between the roll temperature at the melt/roll interface and cooling water velocity.

Hence, the melt temperature during the continuous rheo-extrusion process can be established by combining Equations (5), (6) and (23). In this case, $a$ and $m$ in Equation (6) are constants, and the value of $m$ is less than 0.5. $\tau$ is the time of heat transfer between 
the melt and roll-shoe gap, which mainly is related to the convective heat transfer and the rotational speed of the roll. Figure 7 shows the temperature variation of the Al-6Mg melt in the roll-shoe gap during continuous rheo-extrusion. According to CALPHAD calculation, the density of Al-6Mg (wt.\%) alloy melt is $2.31 \times 10^{6} \mathrm{~g} \cdot \mathrm{m}^{-3}$ and the specific heat is $1.1594 \mathrm{~J} /(\mathrm{g} \cdot \mathrm{K})$ at $700{ }^{\circ} \mathrm{C}$. Based on the above calculation results, for the Al-6Mg alloy prepared by continuous rheo-extrusion, when the cooling water flow rate in the cooling water pipe is $1.5 \mathrm{~m} / \mathrm{s}$ and the melt is poured into the roll-shoe gap at $800{ }^{\circ} \mathrm{C}$, the melt temperature is rapidly dropped to the liquidus temperature within $1.7 \mathrm{~s}$ and completely solidified in $7.5 \mathrm{~s}$. Temperature variation of the Al-6Mg melt in the roll-shoe gap with increasing time during continuous rheo-extrusion is shown in Figure 7. In this cooling condition, the average cooling rate is about $10.3 \mathrm{~K} / \mathrm{s}$.

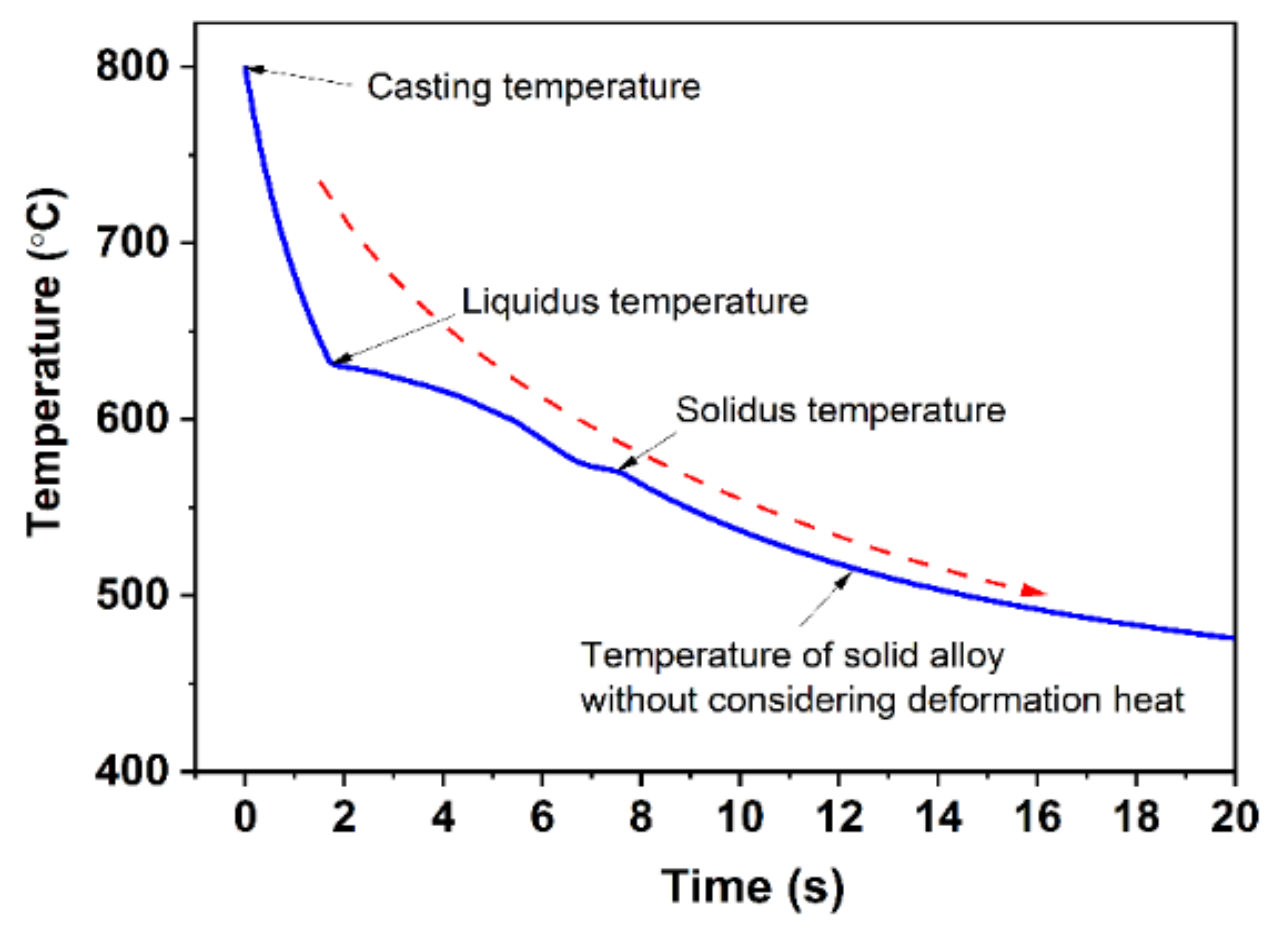

Figure 7. Temperature variation of the $\mathrm{Al}-6 \mathrm{Mg}$ melt in the roll-shoe gap with increasing time during continuous rheo-extrusion.

During continuous rheo-extrusion, it is very difficult to accurately measure the actual melt temperature in the roll-shoe gap due to the complexity of the equipment. After establishing the calculation model, the accuracy of the calculation is indirectly verified by other methods. The solidification microstructure of the Al-6Mg alloy in the roll-shoe gap is obtained by shutdown sampling, as shown in Figure 8a. In addition, the solidification microstructures of Al-6Mg alloys with various cooling rates $(5 \mathrm{~K} / \mathrm{s}, 10 \mathrm{~K} / \mathrm{s}$, and $20 \mathrm{~K} / \mathrm{s}$ ) also are achieved by traditional metal mold casting, as shown in Figure 8b-d. The wall thickness of the mold is different, and the melt temperature is measured and recorded by using a self-made temperature acquisition system. By comparing the average grain size and secondary dendrite arm spacing, the microstructure of the alloy prepared by continuous rheo-extrusion is similar to the solidification microstructure of $10 \mathrm{~K} / \mathrm{s}$. This indicates that the calculated cooling rate $(10.3 \mathrm{~K} / \mathrm{s})$ is within the credible range. 

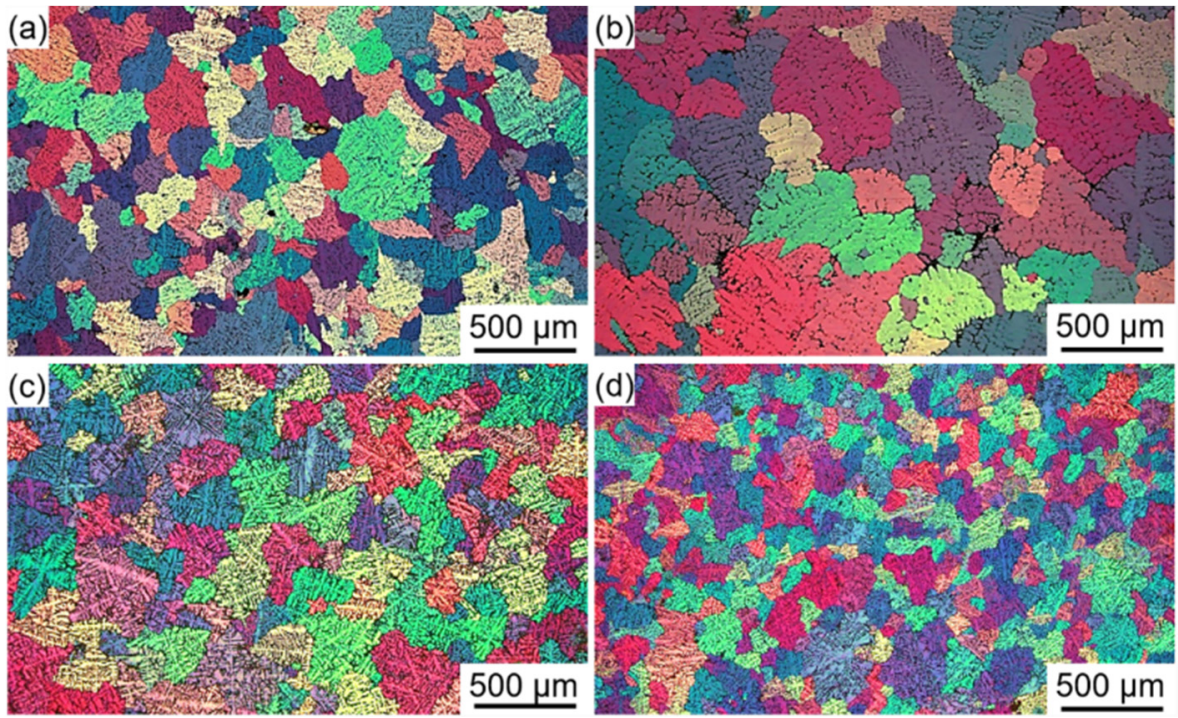

Figure 8. (a) Solidification microstructure of the $\mathrm{Al}-6 \mathrm{Mg}$ alloy in the roll-shoe gap obtained by shutdown sampling; (b-d) solidification microstructures of Al-6Mg alloys with different cooling rates $(5 \mathrm{~K} / \mathrm{s}, 10 \mathrm{~K} / \mathrm{s}$, and $20 \mathrm{~K} / \mathrm{s})$ obtained by traditional metal mold casting.

\section{Conclusions}

This work proposes an estimation methodology to calculate the melt temperature during solidification in the continuous rheo-extrusion process via the basis theory of heat transfer and the CALPHAD calculation. The computational models of heat transfer coefficients acting at the cooling water/roll interface and the melt/roll interface are established. The expression of the relationship between the temperature of the roll at the melt/roll interface and the viscosity of the cooling water is determined. Using this method, the cooling rate of $\mathrm{Al}-6 \mathrm{Mg}$ (wt.\%) alloy melt prepared through continuous rheo-extrusion in the equipment is calculated to be $\sim 10.3 \mathrm{~K} / \mathrm{s}$.

Author Contributions: Conceptualization, R.G. and M.G.; methodology, Y.W. and M.G.; software, J.B.; validation, R.G. and M.G.; formal analysis, Y.W.; investigation, Y.W. and B.Y.; resources, R.G.; data curation, Y.W. and B.Y.; writing —original draft preparation, Y.W.; writing —review and editing, M.G.; visualization, Y.W. and B.Y.; supervision, M.G. and R.G.; project administration, R.G.; funding acquisition, R.G. All authors have read and agreed to the published version of the manuscript.

Funding: This work was supported by the National Key Research and Development Program of China [grant No. 2018YFB2001800] and National Natural Science Foundation of China [grant No. 51871184].

Conflicts of Interest: The authors declare no conflict of interest.

\section{Nomenclature}

$\lambda \quad$ Thermal conductivity, $\mathrm{W} /(\mathrm{m} \cdot \mathrm{K})$

$\lambda_{\mathrm{r}} \quad$ thermal conductivity of low-carbon steel roll

$\lambda_{\mathrm{w}} \quad$ thermal conductivity of cooling water

$\lambda_{\mathrm{m}} \quad$ thermal conductivity of melt

$Q \quad$ Heat, $\mathrm{J}$

$Q_{\mathrm{m}} \quad$ released heat due to the decrease of melt temperature

$Q_{\mathrm{w}} \quad$ heat taked away by the cooling water

$Q_{w r}$ convective heat at the cooling water/roll interface

$Q_{\mathrm{r}} \quad$ heat conducted inside the roll 


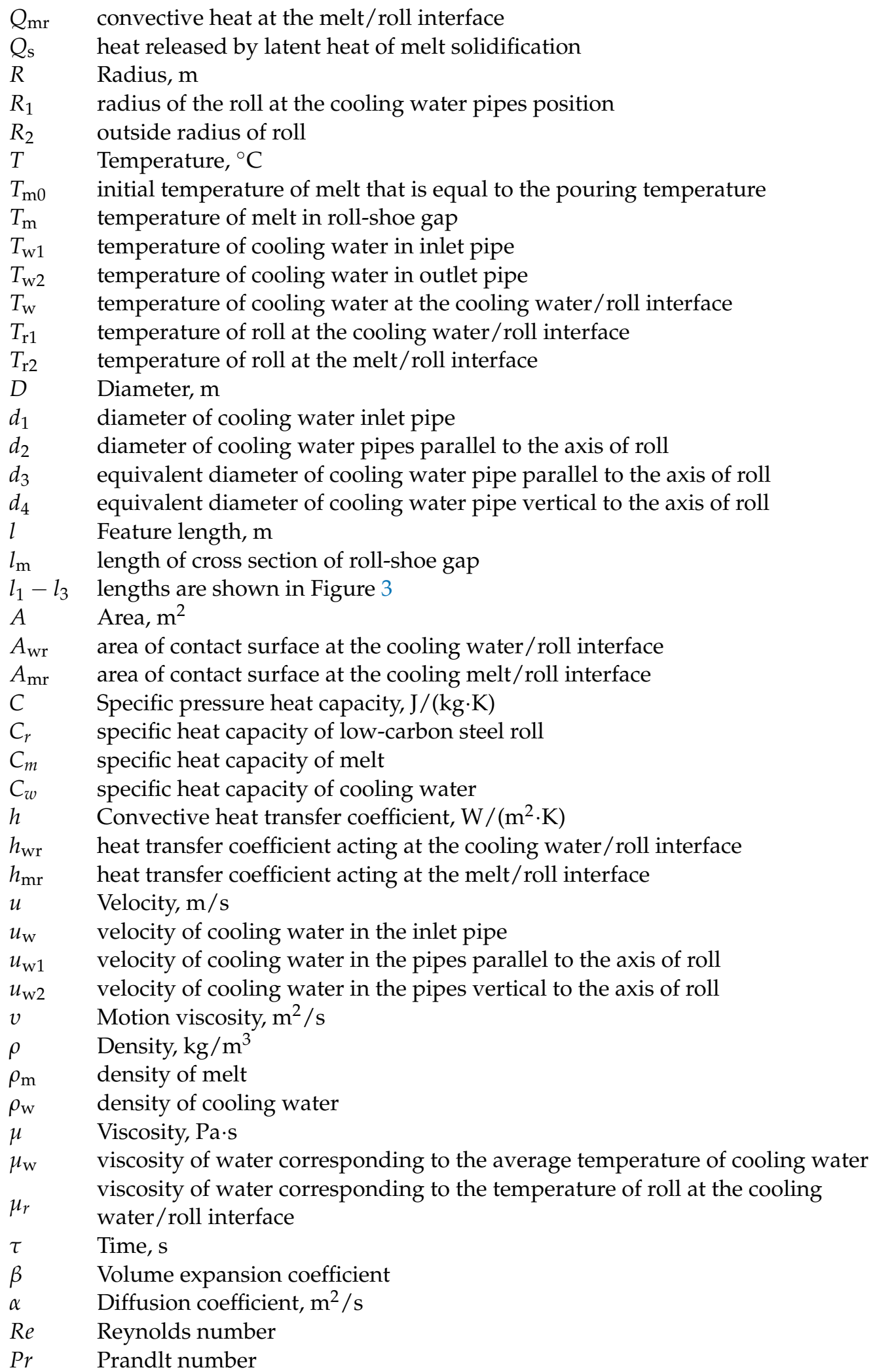

\section{References}

1. Hanizam, H.; Salleh, M.S.; Omar, M.Z.; Sulong, A.B.; Arif, M.A.M. Effects of hybrid processing on microstructural and mechanical properties of thixoformed aluminum matrix composite. J. Alloy. Compd. 2020, 836, 155378. [CrossRef]

2. Duan, Y.L.; Xu, G.F.; Tang, L.; Liu, Y.; Xu, J.W.; Deng, Y.; Yin, Z.M. Excellent high strain rate superplasticity of Al-Mg-Sc-Zr alloy sheet produced by an improved asymmetrical rolling process. J. Alloy. Compd. 2017, 715, 311-321. [CrossRef] 
3. Zang, Q.H.; Feng, D.; Lee, Y.S.; Chen, H.M.; Kim, M.S.; Kim, H.W. Microstructure and mechanical properties of Al-7.9Zn-2.7Mg2.0Cu (wt\%) alloy strip fabricated by twin roll casting and hot rolling. J. Alloy. Compd. 2020, 847, 156481. [CrossRef]

4. Guan, R.G.; Zhao, Z.Y.; Chao, R.Z.; Lian, C.; Wen, J.L. Simulation of temperature field and metal flow during continuous semisolid extending extrusion process of 6201 alloy tube. T. Nonferr. Metal. Soc. 2012, 22, 1182-1189. [CrossRef]

5. Chen, Z.W.; Fan, Q.Y.; Kai, Z. Microstructure and microhardness of nanostructured Al-4.6Cu-Mn alloy ribbons. Int. J. Min. Met. Mater. 2015, 22, 860-867. [CrossRef]

6. Tang, Y.; Wu, Y.; Zhang, Y.; Dai, Y.; Dong, Q.; Han, Y.; Zhu, G.; Zhang, J.; Fu, Y.; Sun, B. Intermittent nucleation and periodic growth of grains under thermo-solutal convection during directional solidification of Al-Cu alloy. Acta Mater. $2021,212,116861$. [CrossRef]

7. Tang, H.P.; Wang, Q.D.; Lei, C.; Wang, K.; Ye, B.; Jiang, H.Y.; Ding, W.J. Effect of cooling rate on microstructure and mechanical properties of sand-casted Al-5.0Mg-0.6Mn-0.25Ce alloy. Acta Metall. Sin. 2019, 32, 1549-1564. [CrossRef]

8. Tang, H.P.; Wang, Q.D.; Lei, C.; Ye, B.; Wang, K.; Jiang, H.Y.; Ding, W.J.; Zhang, X.F.; Lin, Z.; Zhang, J.B. Effect of cooling rate on microstructure and mechanical properties of an Al-5.0Mg-3.0Zn-1.0Cu cast alloy. J. Alloy. Compd. 2019, 801, 596-608. [CrossRef]

9. Pang, S.; Wu, G.H.; Liu, W.C.; Sun, M.; Zhang, Y.; Liu, Z.J.; Ding, W.J. Effect of cooling rate on the microstructure and mechanical properties of sand-casting Mg-10Gd-3Y-0.5Zr magnesium alloy. Mater. Sci. Eng. A 2013, 562, 152-160. [CrossRef]

10. Paliwal, M.; Jung, I.H. The evolution of the growth morphology in $\mathrm{Mg}-\mathrm{Al}$ alloys depending on the cooling rate during solidification. Acta Mater. 2013, 61, 4848-4860. [CrossRef]

11. Souza, E.N.; Cheung, N.; Santos, C.A.; Garcia, A. The variation of the metal/mold heat transfer coefficient along the cross section of cylindrical shaped castings. Inverse Probl. Sci. En. 2006, 14, 467-481. [CrossRef]

12. Liu, Y.L.; Liu, M.; Luo, L.; Wang, J.J.; Liu, C.Z. The solidification behavior of AA2618 aluminum alloy and the influence of cooling rate. Materials 2014, 7, 7875-7890. [CrossRef] [PubMed]

13. Liu, Z.W.; Wang, G.; Yi, J. Study on heat transfer behaviors between Al-Mg-Si alloy and die material at different contact conditions based on inverse heat conduction algorithm. J. Mater. Res. Technol. 2020, 9, 1918-1928. [CrossRef]

14. Ramírez-López, A.; Aguilar-López, R.; Palomar-Pardavé, M.; Romero-Romo, M.A.; Muñoz-Negrón, D. Simulation of heat transfer in steel billets during continuous casting. Int. J. Min. Met. Mater. 2010, 17, 403-416. [CrossRef]

15. Cheung, N.; Santos, N.S.; Quaresma, J.M.V.; Dulikravich, G.S.; Garcia, A. Interfacial heat transfer coefficients and solidification of an aluminum alloy in a rotary continuous caster. Int. J. Heat Mass. Tran. 2009, 52, 451-459. [CrossRef]

16. Dutra, J.C.; Silva, R.E.; Savi, B.M.; Marques, C.; Alarcon, O.E. Metallurgical characterization of the $5083 \mathrm{H} 116$ aluminum alloy welded with the cold metal transfer process and two different wire-electrodes (5183 and 5087). Weld. World 2015, 59, 797-807. [CrossRef]

17. Reza, T.; Reza, E.A.; Mehdi, A.S.; Reza, Y.A. The effect of harmonic vibration with a frequency below the resonant range on the mechanical properties of AA-5083-H321 aluminum alloy GMAW welded parts. Mater. Sci. Eng. A 2018, 736, 248-257. [CrossRef]

18. Bergman, T.L.; Lavine, A.S.; Incropera, F.P.; DeWitt, D.P. Fundamentals of Heat and Mass Transfer, 7th ed.; John Wiley and Sons: Hoboken, NJ, USA, 2011; ISBN 9780470501979.

19. Yang, S.M.; Tao, W.S. Heat Transfer, 4th ed.; Higer Education Press: Beijing, China, 2006; ISBN 9787040189186.

20. Chapman, B. Heat transfer. Magn. Reson. Mater. Phy. 1974, 9, 146-151. [CrossRef] [PubMed] 